\title{
The Tenckhoff catheter in elderly patients with chronic renal failure: placement in spinal anesthesia with open technique, without required location in the hollow of Douglas
}

\author{
T Strazzullo*, G Prestieri, D Di Simone, G Merola \\ From XXIII Annual Meeting of the Italian Society of Geriatric Surgery \\ Lecce, Italy. 2-4 December 2010
}

\section{Background}

Currently there are various techniques for catheter placement for peritoneal dialysis. The purpose of this paper is to describe our technique and our results in elderly patients.

\section{Materials and methods}

We report our experience on the placement of the Tenckhoff catheter (TC) in elderly patients by open surgery, under spinal anesthesia, without necessarily placing the catheter in Douglas.

\section{Results}

Between January 2004 and September 2010 we placed $42 \mathrm{TC}$ in 42 patients including 25 males and 17 females between 65 and 92 years old (mean age 73 years). 7 of these patients were simultaneously subjected to another surgery to correct a defect in the abdominal wall.

Among the 29 patients still living $4 \mathrm{TC}$ are no longer used: 2 for recurrential peritonitis, 1 for considerable volume polycistic kidney disease and 1 was removed due to an undefined failure.

The TC that are currently working are: $4 / 7$ after 6 years, $1 / 2$ after 5 years, $1 / 1$ after 4 years, $1 / 1$ after 3 years, $4 / 4$ after 2 years, $9 / 9$ to 1 years; $5 / 5$ in the last 6 months.

In the post-operative abdomen X-rays were performed in 7 of the 26 patients who showed different locations of the distal end of the catheter: 3 in Douglas, 1 in the left side, 2 in the right side, 1 in the right upper quadrant.

\section{Conclusions}

Placement of the TC under spinal anesthesia with open technique, not necessarily placing the tip in the Douglas, is a simple technique that guarantees good results with low operational risks and peri-operative complications, especially for elderly patients. The results of this technique in combination with concomitant hernias are particularly relevant.

Published: 24 August 2011

\section{References}

1. Chow KM: Tenckhoff catheter insertion by nephrologists: open dissection technique. Perit Dial Int 2010, 30(5):524-7.

2. Yang PJ: Mini-laparotomy implantation of peritoneal dialysis catheters: outcome and rescue. Perit Dial Int 2010, 30(5):513-8.

3. Mettang T: Endoscopic transluminal insertion of a peritoneal dialysis catheter. Perit Dial Int 2010, 30(1):63-5.

4. Pantea S: The placement of Tenckhoff peritoneal dialysis catheter by laparoscopic approach-our experience. Chirurgia 2008, 103(6):669-72.

5. Ashegh $\mathrm{H}$ : One-port laparoscopic technique for placement of Tenckhoff peritoneal dialysis catheters: report of seventy-nine procedures. Perit Dial Int 2008, 28(6):622-5.

doi:10.1186/1471-2318-11-S1-A61

Cite this article as: Strazzullo et al: The Tenckhoff catheter in elderly patients with chronic renal failure: placement in spinal anesthesia with open technique, without required location in the hollow of Douglas. BMC Geriatrics 2011 11(Suppl 1):A61.

* Correspondence: segreteriadisalvo@gmail.com

Departement of Surgical, Anaestesiologic and Emergency Sciences,

University Federico II , Naples, Italy 